\title{
Psicoterapia preventiva da família
}

\author{
Ryad Simon
}

$\mathrm{P}$

sicoterapia preventiva da família é o nome que assumiu um procedimento de atendimento e pesquisa de. senvolvido pelos membros da Sociedade de Psicologia Clínica Preventiva nestes últimos oito anos. Um dos âmbitos de estudo de nossa Sociedade é a comunidade. Como meio de alcançar a comunidade partimos da família.

\section{Finalidade}

O psicólogo preventivo assume que seu cliente ê a família. Quando ele se fixa nesse objetivo, seguem-se consequiências inerentes a essa posição. Por exemplo, quando a família acha que apenas um dos membros precisa de assistência, o psicólogo não contraria essa opinião. Todavia, fica alerta para captar as ramificaçōes do relacionamento desse membro da família com todos os demais. $\mathrm{E}$, desse modo, alcançar uma visāo muito mais ampla da interdependencia das ações e reações de cada componente da família. Essa visão seria muito mais restrita se o psicólogo apenas cuidasse do membro da família que o procura, ou lhe é encaminhado, como no atendimento tradicional.

A amplitude do conhecimento da diversidade de fatores que influem na adaptaçāo de cada pessoa vai tornar mais rico o entendimento do psicólo. go. A abundância de conhecimentos permitirá estruturar um plano de atendimento mais exato. Tendo uma noção mais precisa de qual ć o núcleo do problema, a intervenção preventiva é mais eficaz. Da própria eficácia resulta que o tempo necessário para alcançar determinado efeito será mais curto.

Tornando-se a psicoterapia pre-

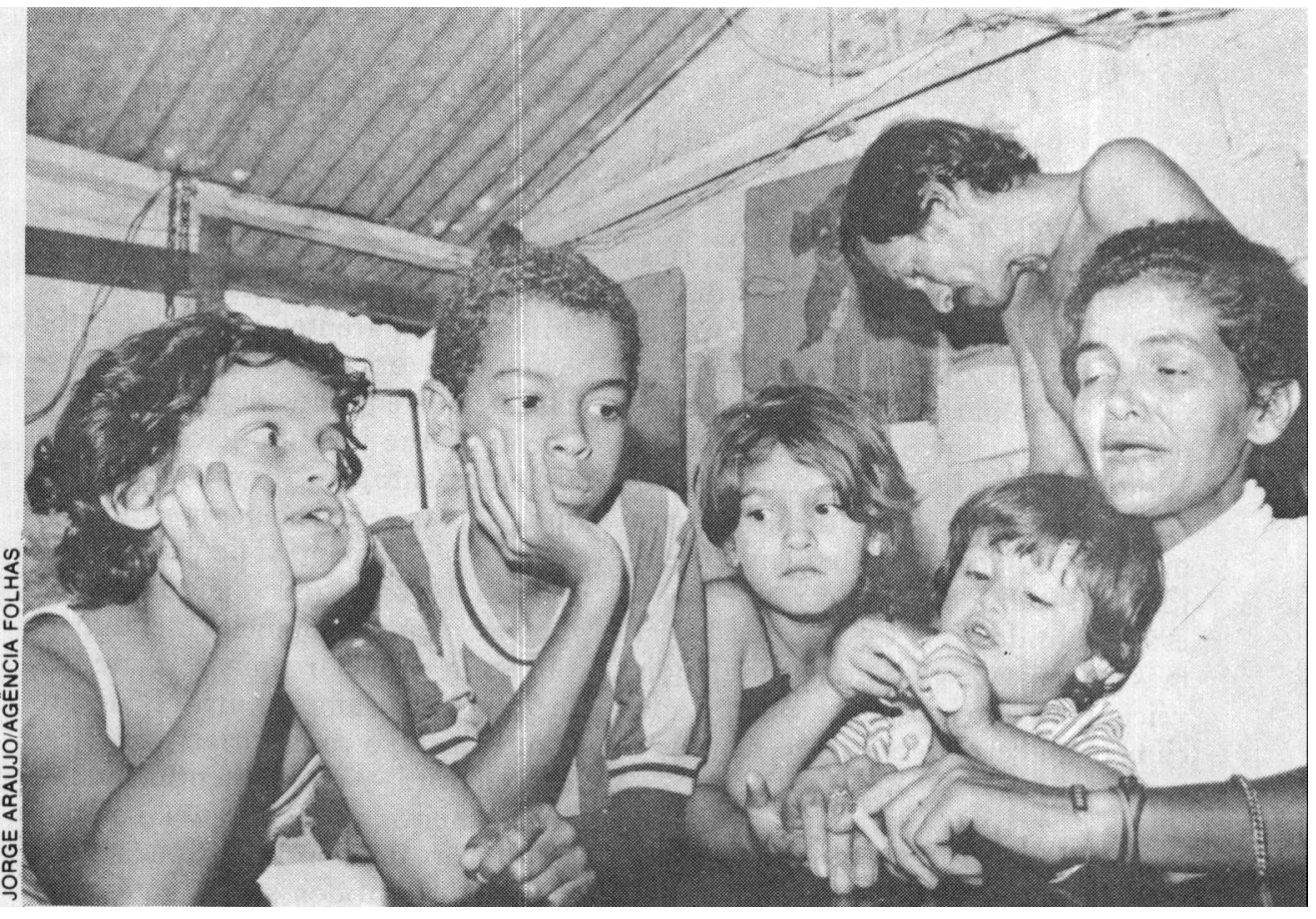

ventiva da família mais eficaz e mais breve, os custos se tornarão mais acessíveis a maior número de pessoas. Assim, cada família atendida irá assimilando uma mentalidade preventiva. ("Mentalidade preventiva" resulta de uma transmissão de conhecimentos à família objetivando alertá-la para os sinais precoces de distúrbios adaptativos - para que os corrija - bem como elevar o nivel de exigência existente, de modo a tornar ainda mais eficaz uma adaptaçāo que já é adequada "promoção de saúde"). Não é difícil supor - e de fato acontece - que cada família sentido-se bem assistida irá divulgar para as próximas a utilidade da ajuda preventiva. E, pouco a pouco, num contágio benéfico, irão se estendendo ramificaçōes formando uma rede que fortalece a saúde psíquica e protege a comunidade contra formas de adaptação menos eficazes $\left({ }^{*}\right)$

\section{Método, Objetivos e Discussão}

A ida do psicólogo ao domicílio da família possibilita-lhe uma percepção direta do ambiente material e relacional familiar. Pode-se objetar

(") "Adaptação mais (ou menos) eficaz" é um conceito que foi operacionalizado em meu livro "Psicologia Clínica Preventiva" (Simon, R. 1983). Significa genericamente que o conjunto das soluçōes encontradas para os problemas vitais permitem gratificaçŏes qualitativas e quantirativas e, também, produzem relativamente reduzidos conflitos intrapsíquicos e ambientais. 
quanto à "pureza" da observação, visto que a presença do observador no campo domiciliar altera o objeto observado. De fato, haverá famílias que arrumam melhor a casa quando esperam a visita do psicológo. Todavia, isso em si já é um dado. E que dizer das famílias que, sabendo embora da visita domiciliar, mal se preocupam em ocultar a desordem? A visão de uma casa suja, desarrumada, com crianças e animais e atropelando, desperta rapidamente sentimentos e compreensão da desorganização familiar que de outro modo, no consultório, por exemplo, só tarde ou nunca seriam captadas. (A "desorganização familiar" pode geralmente ser evidenciada pela incapacidade de ordem material da dona de casa; e isso, por sua vez, reflete sua desorganização intrapsiquica que termina por contaminar a família, principalmente as crianças. A desordem que está "fora" da cabeça - projetada - está também introjetada - "dentro" da cabeça.)

Por outro lado, as interaçöes familiares no domicílio são supostamente mais espontâneas e menos inibidas do que se verificadas em outro local. Assim, o psicólogo pode observar no domicílio uma pessoa isolada, uma dupla, ou a familia inteira, colhendo rapidamente fartas informações. Estas informaçōes tanto podem ser materiats (qualidade e estado do ambiente físico) transferenciais (de cada familiar para o psicólogo) extratransferenciais (relaçōes dos familiares entre si) contra-transferenciais (reaçōes do psicólogo face o ambiente c os membros da família). É claro que essas informaçōes serão muito mais nítidas e aproveitáveis quanto mais confortável o psicólogo se sinta no domicílio. E quanto mais à vontade consiga deixar a família com sua presença. Essas consideraçōes sugerem que o psicológo, saindo do consultório e indo para o domicílio, assemelha-se ao explorador diante de uma cultura alienígena. E que ele precisará desenvolver métodos que são mais do âmbito do antropólogo do que do clínico. Assim como já existe uma Psicologia Social precisamos desenvolver uma Psicologja Antropológica específica.

Ao procurar uma família, ou ser procurado por ela, o psicólogo inicia pelo diagnóstico. Concebe-se a evolução familiar como um processo que se opera no tempo. Ao efetuar o diagnóstico, o psicólogo executa dois cortes no processo evolutivo temporal. Um corte transversal, que fornece os fatos do presente (imediato ou próximo). Esse corte contém os elementos da situação-problema atual. Ele inclui a "queixa". Geralmente a queixa é apenas um aspecto - e não o mais importante - da situação-problema (que até pode estar inconsciente para os familiares). A investigação do corte transversal dá as respostas às seguintes perguntas da situação-problema: "o quê?" "quen?" e "como?" O que está acontecendo agora? Quem está envolvido? Como é o envolvimento? O corte longitudinal completa o diagnóstico do processo da evolução familiar remetendo-nos ao passado. Ele responde às perguntas: "onde?" "quando?" e "por quê?" Onde ocorreu o problema? Quando começou o envolvimento? Por que aconteceu? As respostas a todas essas perguntas permitem-nos compreender a trama do relacionamento familiar. Atualmente estudamos técnicas de diagnóstico que nos possibilitem obter o diagnóstico preventivo familiar, no máximo em três entrevistas.

Concluído o diagnóstico, passase, quando for o caso, à psicoterapia preventiva da família, propriamente dita. Obedece a uma estratégia diretiva. O psicólogo procura ativamente dar aos familiares uma compreensão afetiva dos elernentos da situaçãoproblema. Para ser acessível à maioria da população, a psicoterapia preventiva deve ser breve. Conforme a complexidade da situação-problema traça-se uma plano psicoterápico que abrange de uma a doze sessões. A abordagem é flexível, dirigindo-se ora a um, ora a outro, ou mais membros da família. A técnica é eclética, usando-se ora abordagens suportivas (reasseguramento, persuasão, orientação, modificaçōes ambientais, etc), ora psicodinâmicas (explicação dos dinamismos inconscientes das relaçōes familiares, e, quando necessário, interpretação da transferência e das resistências).

O alcance da psicoterapia preventiva da família compreende desde os sintomas individuais até as dificuldades de ajustamento intra ou extrafamiliares.

O objetivo é promover a integração familiar a níveis de adaptação mais eficazes. Para alcançar esse obje- tivo faz-se um seguimento preventivo a cada três meses. Desse modo é verificado periodicamente o estado de adaptação familiar, independente de haver chamada para ajuda psicológica. A família vai compreendendo pela experiència o que significa prevenção primária. Assim, o atendimento preventivo da família combina dois modelos de assistência psicológica: um método breve, quando surge um problema situacional (e cai no âmbito da prevenção secundária ou terciária) e um método de atendimento por prazo indeterminado, que visa manter e melhorar o nivel de eficácia adaptativa da família (âmbito da prevenção primária):

Com o intuito de ilustrar como se processa a psicoterapia preventiva da tamília, cito um atendimento relativamente simples. Uma familia composta de quatro pessoas: 0 casal $e$ duas filhas de 9 e 6 anos, na ocasião do início do atendimento. A queixa era e que a filha mais nova, apresentava mau aproveitamento escolar e não iria ser aprovada no exame para ingresso numa escola muito conceituada e muito exigente. Essa escola era frequientada pela irmã mais velha e todos os filhos dos parentes próximos. Para os pais era uma questão de honra que a filha ingressasse nessa escola. A psicóloga incumbida do atendimento conclui que a criança problema, $\mathbf{M}$, tinha inteligência normal. Pela investigação da dinâmica familiar verificou que a menina sofria de carência afetiva. Os pais trabalhavam fora de casa. Ela usava o mau aproveitamento escolar como forma de obter afeto dos pais. M, comumente, telefonava para a mãe no local de trabalho, angustiando-a com queixas de mal-estar físico. Se os pais estavam apreensivos com o êxito escolar de $M$, esta aproveitava esse fato para obter toda atenção possível. A solução terapêuutica era aparentemente simples. Se $M$ obtinha afeto com sua inferioridade escolar, bastava que os pais deixassem de demonstrar angústia nessa situação. Cessaria o ganho que $M$ obtinha e desapareceria o motivo para ser uma estudante relapsa. Mas a recomendação não pôde ser facilmente acatada, principalmente pelo pai, que se angustiava muito com a insuficiência escolar de $M$.

Aprofundando as investigaçōes, verificou-se que o pai, na infância, fora por sua vez um estudante inefi- 
ciente, tendo sido rejeitado por isso. Mais tarde, quando se candidatara à mão da futura esposa, a família desta fizera-lhe restriçöes. Assim, o pai precisava provar para a familia da sogra que suas filhas eram excelentes estudantes, para desmentit os prognósticos desfavoráveis na ocasião do namoro. É claro que tudo isso que a psicóloga apurou era inconsciente para os familiares. Assim, o pai de $\mathbf{M}$ pôde perceber que estava submetido às figuras paternas de sua infância. $E$, posteriormente, aos sogros rejeitadores com quem se identificava e, por isso, atormentava $\mathrm{M}$. Ao ser possível mostrar-lhe que sua filha $M$ estava nas mesmas condições de quando o pai era criança, este pôde identificarse com a filha. Sua atitude mudou de crítica para simpática. M, obtendo gratificação afetiva direta, dispensou o método antigo, melhorou nos estudos e ingressou na escola pretendida. Continuando o atendimento trimestral nas visitas periódicas preventivas a psicóloga obteve um quadro mais amplo da situação e sua relação com as familias dos parentes. $\mathrm{A}$ mãe de $\mathrm{M}$ também fora uma criança rejeitada pelos familiares. Assim, se $\mathbf{M}$ era o bode expiatório da família, seus pais, quando crianças, também o haviam sido. A família de $\mathrm{M}$, em seu conjunto, era rejeitada pelas outras famílias de parentes, isto $\varepsilon_{\text {, era uma familia }}$ bode-expiatório. Em sintese, tínhamos começado com uma criança que era bode-expiatório da familia, e constatamos que a família por sua vez era bode-expiatório das famílias parentais. Dificilmente chegaríamos a essa amplitude de conhecimento se restringíssemos o atendimento apenas ao consultório. A psicóloga trabalhou essa circunstância dando apoio afetivo aos pais, desenvolvendo sua autoestima, ajudando-os a serem mais assertivos com as famílias dos parentes. Sugeriu-lhes que se tornassem menos dependentes, procurando contatos com famílias diferentes. Discutiu os problemas inter-farniliares, estimulando a rebelião contra a submissão. $\mathrm{E}$ assim, aos poucos, melhorou a integração intra-familiar, e aumentou a auto-estima $e$ indepedência no contato extra-familiar.

\section{Méritos}

$\mathrm{O}$ atendimento preventivo da família tem vários méritos. Cito os mais importantes. a) Promovendo um seguimento trimestral indefinido desenvolve uma mentalidade de assistência preventiva permanente. b) Essa vigilância preventiva corresponde a um seguro de saúde mental familiar pouco oneroso. c) Em termos de prevenção secundária ou terciária, o procedimento de ir em busca de familias dentro da comunidade permite alcançar casos que só muito tarde ou nunca iriam procurar ajuda especializada. E assim se pode evitar o agravamento ou a cronicidade de muitos distúrbios de adaptação, poupando sofrimento desnecessário a grande número de pessoas. d) Nosso modelo alternativo de atendimento liberta o psicólogo e a comunidade da dependência governamental. Isso não é pouca coisa, considerando os vícios dos serviços públicos. Os mais graves sendo a ineficiência burocrática, a impessoalidade no atendimento, a diluição da responsabilidade no anonimato institucional. En nosso modelo é sempre o mesmo psicólogo que cuida da mesma família, que conhece $O$ atendimento completo e assume pessoalmente o vínculo afetivo e a responsabilidade pelo trabalho preventivo. e) Amplia a área de atuação do psicólogo para além do consultório. O psicólogo pode ocupar as horas vagas no consultório assumindo o atendimento preventivo da família. Por outro lado há muitos psicólogos que gostariam de trabalhar em clínica, mas não têm recursos para montar consultório. Nem seria econôtmico se o fizessem, por falta de clientes. Todavia, esse psicólogo que precisa trabalhar em outra área por motivos de subsistência, adotando nosso modelo preventivo poderia dispensar a infra-estrutura consultorial e dar assistência em horário não-comercial. A Sociedade de Psicologia Clínica Preventiva oferece-lhe um curso de especialização, supervisão do atendimento, grupo para pesquisa e discussão das experiências, e um banco de famílias esperando assistência.

\section{Conclusōes}

Em suma, $o$ atendimento preventivo da família tem um princípio: o cliente é a família; um método: o trabalho é domiciliar, com técnicas de psicoterapia breve; um propósito: seguimento interminável com intuito de vigilância preventiva; um fim: cobrir todas as fases da prevenção - primária, secundária e terciária.
Visto que na Sociedade de Psicologia Clínica Preventiva somos todos psicólogos trabalhando por amor à pesquisa, temos somente o escasso tempo livre para investigar. Nosso conhecimento vai avançando lentamente. Convidamos os interessados a juntarem-se a nós para ampliarmos nosso esforços.

Quando Freud deixou a hipnose pelo método da associação-livre, descobriu a Psicanálise. Quando Melanie Klein adotou o método da ludoterapia, trouxe vários progressos à psicanálise. $\mathrm{O}$ atendimento preventivo $\mathrm{da}$ família é um campo novo, que aguarda o aparecimento de seus Freud c Melanie Klein. Mas para encontrá-los é preciso estar trabalhando.

Para finalizar,abordo o lado prático e seus problemas atuais. A Sociedade de Psicologia Preventiva tem procurado funcionar de dois modos nessa área da comunidade. De um lado, dando formação aos psicólogos através de cursos de especialização. De outro, servindo como centro de coordenação dessa assistência preventiva à família. Nesse duplo funcionamento nem tudo são rosas. Do lado do psicólogo, temos que o profissional mais experiente, acostumado à segurança $e$ às técnicas mais conhecidas do trabalho em consultório, dificilmente se dispöe a arriscar-se nesse campo desconfortável $e$ incerto do atendimento domiciliar. A solução é contar com psicólogos novos, não "viciados" nas comodidades tradicionais, mas também sem experiência e com pouco conhecimento para lidar em área tão complexa. Por conseguinte, são muitas as frustrações, desencantos e angústias. Poucos suportam todas essas vicissitudes. Quanto às famílias atendidas, habituadas a uma assistência paternalista gratuita, dificilmente se prestam a pagar os módicos preços do atendimento domiciliar e que mal bastam para custear as despesas do psicólogo. Esses são os percalços e desencanto nessa árdua tarefa de disseminar os princípios da Psicologia Clínica Preventiva.

SIMON, R. - Psicologia Clinica Preventiva - Novos - Fundamentos- São Paulo: Vetor - Editora Psicopedagógica, 1983. Ediçāo esgotada. Será reeditado pela E.P.U. - Editora Pedagógica Universitária, também de São Paulo, no 20 semestre de 1989). 